\title{
The Iranian Integrated Care Electronic Health Record
}

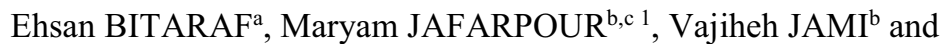 \\ Fatemeh SARANI RAD ${ }^{b}$ \\ ${ }^{a}$ Center for Statistics and Information Technology, Iran University of Medical Sciences \\ ${ }^{\mathrm{b}}$ Center for Statistics and Information Technology, Ministry of Health and Medical \\ Education
}

\begin{abstract}
E-health plays a crucial role in E-government by proposing healthcare services based on information technology. However, the way to administer these services by using E-health solutions is one of the challenging issues. One of these significant challenges is how one integrates heterogeneous healthcare information of the different point of care systems. This paper introduces the Iranian integrated care electronic health record using the information gathered from several point-ofcare systems in healthcare enterprises in Iran. This service-oriented architecture has a remarkable characteristic - its accessibility to medical knowledge and medical concepts through archetypes and ontology, respectively. The Ministry of Health and Medical Education of the Islamic Republic of Iran has designed and implemented this national architecture.
\end{abstract}

Keywords. Medical Records Systems, Systems Integration, Archetype, Ontology, Iranian Integrated Care Electronic Health Record (SEPAS), Service-Oriented Architecture (SOA)

\section{Introduction}

The Data provided by the healthcare system is extremely vital because of its role in the improvement of healthcare performance, epidemiological analysis, evidence-based practices, health quality control, clinical pharmacy practices, medical education, and public health cost reduction [1], [2]. Integration of healthcare information promotes the usability and availability of this invaluable information. Nowadays, many countries dedicate a part of their eHealth strategic plans to the design and implementation of electronic health records (EHR) as one of their priorities. Many countries have started efforts in this regard, some of which are mentioned in [3-9]. Since 2005 a national commitment was formed in Iran to implement National Integrated Care Electronic Health Record (ICEHR) which is called SEPAS, locally. Therefore, the Ministry Of Health and Medical Education (MOHME) has developed a national e-health vision in collaboration with relevant stakeholders who need access to integrated healthcare information including organizations responsible for management and supervision of the healthcare system, organizations related to medical education and research, etc. [10]. Thus, it is necessary to overcome a problem regarding the lack of a suitable system to

\footnotetext{
${ }^{1}$ Corresponding Author, E-mail: m.jafarpour@ut.ac.ir
} 
integrate this invaluable information. In this paper, SEPAS is introduced based on the OpenEHR Architecture model.

\section{Materials and Methods}

This paper is based on a literature study and on interviews with the technical and relevant stakeholders of the electronic health record implementation at the Ministry of Health and Medical Education. Since there is a diverse range of stakeholders in the EHR implementation domain, the interviews were conducted in semi-structured form. Many other previous pieces of research have followed the interview approach $[11,12]$. Approval for this research was obtained from MOHME. According to the interviews as well as the review on the related literature, the national integrated care electronic health record design requires some steps that are going to be explained in this section.

\subsection{Study on systems Integration Methods}

The term Systems Integration is defined as the process of linking several different computing systems physically or functionally to act as a coordinated whole [13]. The healthcare sector is broad, consisting of several heterogeneous Information Systems; thus, it is necessary to know integration methods to combine these Information systems. There are three systems integration methods including, vertical integration, star integration, and horizontal integration. The methods of integration are studied thoroughly to realize their effects on the national architecture.

\subsection{Study on interoperability standards}

In healthcare, interoperability is the ability of different information technology systems and software applications to communicate, exchange data, and use the information that has been exchanged [14]. Data exchange schema and standards should permit data to be sharable across clinicians, lab, hospital, pharmacy, and patient regardless of the system or system vendor. There are two levels of data interoperability that discussed in the following subsections.

\subsubsection{Functional interoperability}

Functional interoperability is the benefits of joined-up healthcare to provide the right information at the right time and place, depending on computer systems being able to exchange information in a way that is safe, secure, and reliable [4].

\subsubsection{Semantic interoperability (SI)}

SI is necessary for automatic computer processing to underpin the value-added EHR clinical applications [15]. Archetypes are suitable solutions for SI [16]. According to CEN/ISO 13606 standard, an archetype is an information model of the metadata to represent the domain-specific attributes of any EHR by specifying values or constraints in the EHR reference model [17]. However, it is necessary to adopt clinical terminology in EHRs to ensure high-level SI [18], [19]. 


\subsection{Conceptual Architecture Design}

The objective of designing the conceptual architecture is to identify the component structure(s), their externally visible properties, and their relationships [20]. The conceptual architecture is inferred after the following actions.

1. Stakeholders Identification: The first step was to identify all significant enterprises which are producers or consumers of health information. Besides, any types of healthcare information to be produced or consumed were analyzed and categorized. In this regard, some health sector stakeholders participated in interviews. These stakeholders include health policymakers, healthcare providers (GPs, Specialists, and nurses, etc.), insurance organizations, emergency departments, research centers, medical universities, etc.

2. Point of care systems Identification: In this step, any existing patient-centric health information systems in the country were identified and categorized. The technical team interviewed healthcare facility workers for the information systems being used by them.

3. Modeling present state: In this step, some important use cases in the healthcare sector were identified and modeled. A standard approach to model the presentstate was to depict the activity diagrams, entities, actors, and rules. A list of the defects of the present-state was compiled consisted of any items from financial issues to the equal allocation of resources among the healthcare facilities.

4. Modeling desired state: In this step, the identified components were re-modeled considering that the integrated care EHR exists.

\section{Results}

The eHealth implementation efforts in Iran [10] lead to a national architecture that is called SEPAS, locally. The architecture of the Iranian Integrated Care EHR System (SEPAS) is service-oriented and distributed. This means that Instances of architecture would be installed in different geographical locations. It was decided to position each instance in medical universities since all healthcare facilities are providing care services under the supervision of medical universities. Due to rapid changes in medical knowledge, to deal with these changes, two-level architecture is adopted according to ISO 13606. The first level is the reference information model which is stable, while archetypes and templates constitute the second level. The Iranian ICEHR consists of 3 layers that are going to be discussed in the following subsections. These layers together build up an instance of EHR node. Each instance of EHR is called SEPAS middleware or SEPAS node. The functionality of SEPAS node is similar to the definition of sharable EHR (level 3) [21]. SEPAS consists of several layers including, the Data layer, Core Service Layer, Domain Service Layer, which are going to be explained elaborately, later.

\subsection{The Data Layer}

This layer consists of several data repositories according to ISO 13606, such as EHR, demographic, terminology, service log, and archetype. The archetype repository can manage archetypes and templates and their versions. These archetypes represent models for demographics, symptoms, physical examination, laboratory, etc. Currently, ISO/EN 
13606, HL7 Clinical Document Architecture, and the OpenEHR represent the most famous dual models $[22,23]$. Existing implementations of the archetype enabled EHRs to auto-generate entry forms from archetype and template [24-28].

\subsection{Core Service Layer}

Core services provide data and message management to achieve the dual model approach of EHR architecture. This layer is implemented based on ISO 13606 part 5. It consists of the following services: extract manager, locator, archetype, ontology, and audit trail service.

\subsection{Domain Service Layer}

The national architecture implementation in the country showed that the legacy systems (POCSs) are not compatible with the international standards (i.e. ISO 13606). Thus, the technical team added a layer called the domain service layer. Inspired by the archetype concept, some web services were implemented in this layer. They hide the complexities of dealing with archetypes from the legacy systems. Also, this layer interoperates with the core services to transform the non-standard data structures of POCSs. Table 1 shows some of these services.

Table 1. Some of domain services in SEPAS

\begin{tabular}{ll}
\hline \multicolumn{1}{c}{ Domain Service } & \multicolumn{1}{c}{ Description } \\
\hline Inpatient Service & Discharge summaries of inpatient data from Hospitals \\
Medication Prescription Service & Prescribed medications from hospitals, clinics, etc. \\
Dispensed Prescription Service & Dispensed prescriptions form pharmacies \\
Laboratory Prescription Service & Laboratory Test Requests from clinics, etc. \\
Laboratory Result Service & Designed to interchange laboratory test results \\
\hline
\end{tabular}

\section{Conclusions}

In this paper, a decentralized service-oriented architecture is discussed. Many countries have followed the same approach as this paper, for many reasons including the diversity of the information systems, healthcare facilities, etc. [3-8]. Implementing such architecture at the national level is faced with some obstacles. Apart from barriers like persuading healthcare providers to use information systems and lack of public awareness [29], there are several barriers for healthcare information integration including, data exchange standards and terminologies [30] and multiple POCSs [31]. Furthermore, advances in medical sciences and information technology make it necessary to select a flexible architecture for EHRs. These points are covered in some architectures like the OpenEHR that gradually became a standard in this field [32]. SEPAS is planned to be extended in various directions such as the development of clinical contents for EHR using archetypes and its utilization for clinical registries, in the country.

\section{References}

[1] Cebul RD. Using electronic medical records to measure and improve performance. Trans Am Clin Climatol Assoc. 2008;119:65. 
[2] Kay M, Santos J. Report on the world health organization global observatory for eHealth strategic planning workshop, April 2008. Methods of information in medicine. 2008;47(04):381-7.

[3] Box TL, McDonell M, Helfrich CD, Jesse RL, Fihn SD, Rumsfeld JS. Strategies from a nationwide health information technology implementation: the VA CART story. J Gen Intern Med. 2010;25(1):72-6.

[4] Jian WS, Hsu CY, Hao TH, Wen HC, Hsu MH, Lee YL, Li YC, Chang P. Building a portable data and information interoperability infrastructure - framework for a standard Taiwan Electronic Medical Record Template. Computer methods and programs in biomedicine. 2007 Nov 1;88(2):102-11.

[5] Giokas D. Canada health Infoway-towards a national interoperable electronic health record (EHR) solution. Studies in health technology and informatics. 2005 Jan 1;115:108-40.

[6] De La Torre-Díez I, González S, López-Coronado M. EHR systems in the Spanish Public Health National System: the lack of interoperability between primary and specialty care. Med Syst. 2013;37(1):1-7.

[7] Bos L. Sharable EHR systems in Finland. Medical and Care Compunetics 3. 2006 May 31;121:364.

[8] Veseli H, Kopanitsa G, Demski H. Standardized EHR interoperability: preliminary results of a German pilot project using the archetype methodology. Stud Health Technol Inform. 2012;180(180):646-50.

[9] Bourne DE, Hanmer LA, Heavens KJ. Towards developing a national health information standards framework for South Africa. International journal of medical informatics. 1998;48(1-3):29-31.

[10] Riazi H, Jafarpour M, Bitaraf E. Towards National eHealth Implementation-A Comparative Study on WHO/ITU National eHealth Strategy Toolkit In Iran. MIE 2014 (pp. 246-250).

[11] Noblin A, Cortelyou-Ward K, Cantiello J, Breyer T, Oliveira L, Dangiolo M, Cannarozzi M, Yeung T, Berman S. EHR implementation in a new clinic: a case study of clinician perceptions. Journal of medical systems. 2013 Aug;37(4):1-6.

[12] Yoon-Flannery K, Zandieh S, Kuperman G, Langsam D, Hyman D, Kaushal R. A qualitative analysis of an electronic health record (EHR) implementation in an academic ambulatory setting. Inform Prim Care. 2008;16(4):277-84.

[13] Ruh WA, Maginnis FX, Brown WJ. Enterprise application integration: a Wiley tech brief. Wiley; 2002.

[14] HIMSS dictionary of healthcare information technology terms, acronyms, and organizations, HIMSS.

[15] ISO T. 20514: 2005 health informatics-electronic health record definition, scope and context standard. International Organization for Standardization (ISO), Geneva Switzerland. 2005.

[16] Wollersheim D, Sari A, Rahayu W. Archetype-based electronic health records: a literature review and evaluation of their applicability to health data interoperability and access HIM J. 2009 Jun;38(2):7-17.

[17] Kalra D, Beale T, Lloyd D, Heard S. Electronic health record communication part 2: archetype interchange specification. Geneva: ISO. 2008:13606-2.

[18] Park HA, Kim HY, Min YH. Use of clinical terminology for semantic interoperability of electronic health records. Journal of the Korean Medical Association/Taehan Uisa Hyophoe Chi. 2012 Aug 1;55(8).

[19] Garde S, Knaup P, Hovenga EJ, Heard S. Towards semantic interoperability for electronic health records. Methods of information in medicine. 2007;46(03):332-43.

[20] Pressman RS. Software engineering: a practitioner's approach. Palgrave Macmillan; 2005.

[21] Geraci A. IEEE standard computer dictionary: Compilation of IEEE standard computer glossaries. IEEE Press; 1991.

[22] Dolin RH, Alschuler L, Boyer S, Beebe C, Behlen FM, Biron PV, Shabo A. HL7 clinical document architecture, release 2. Journal of the American Medical Informatics Association. 2006;13(1):30-9.

[23] Bointner K, Duftschmid G. HL7 template model and EN/ISO 13606 archetype object model-a comparison. Stud Health Technol Inform. 2009;150:249.

[24] Brass A, Moner D, Hildebrand C, Robles M. Standardized and Flexible Health Data Management With an Archetype Driven EHR System (EHRflex). Stud Health Technol Inform. 2010;155:212-8.

[25] Chen R, Klein GO, Sundvall E, Karlsson D, Åhlfeldt H. Archetype-based conversion of EHR content models: pilot experience with a regional EHR system. BMC Med Inform Decis Mak. 2009;9(1):1-3.

[26] Menárguez-Tortosa M, Martínez-Costa C, Fernández-Breis JT. A generative tool for building health applications driven by ISO 13606 archetypes. Journal of medical systems. 2012 Oct;36(5):3063-75.

[27] Van der Linden H, Austin T, Talmon J. Generic screen representations for future-proof systems, is it possible?: There is more to a GUI than meets the eye. Comput Methods Programs Biomed. 2009;95(3):213-26.

[28] Duftschmid G, Chaloupka J, Rinner C. Towards plug-and-play integration of archetypes into legacy electronic health record systems: the ArchiMed experience. BMCMedInformDecisMak. 2013;13(1):1-2.

[29] Shields AE, Shin P, Leu MG, Levy DE, Betancourt RM, Hawkins D, Proser M. Adoption of health information technology in community health centers: results of a national survey. Health Affairs. 2007;26(5):1373-83.

[30] Huff SM. Clinical data exchange standards and vocabularies for messages. ProcAMIASymp. 1998. p. 62.

[31] Valdes I, Kibbe D, Tolleson G, Kunik M, Petersen L. Barriers to proliferation of electronic medical records. Informatics in Primary Care. 2004;12(1):3-9.

[32] Kalra D, Beale T, Heard S. The openEHR foundation Stud Health Technol Inform. 2005;115:153-73. 